\title{
An Experience of a Tertiary Center for 9 Years on Patients with Surgical and Percutaneous Closure of Atrial Septal Defects
}

\section{Abstract}

Introduction: Atrial septal defect (ASD) is one of the most common congenital cardiac disease, accounts for $7-10 \%$ of all congenital heart diseases in children and $30-33 \%$ in adults. Although ASD usually asymptomatic, it can lead to exercise intolerance, atrial arrhythmia, right ventricular dysfunction, and pulmonary.

Methods: We retrospectively evaluated the observational cohort who underwent transcatheter or surgical closure of ASD. Treatment options were determined according to the guidelines. We retrospectively collected patients' demographic characteristics, pre/post-procedure echocardiography outcomes, complication rates.

Results: Demographic features are similar in both groups. Defect size and valvular pathologies are more frequent in surgical group. Hospitalization duration is longer in surgical groups.

Conclusion: As a conclusion if the patients are evaluated and selected carefully, both surgical and percutaneous closure is convenient and successful in the treatment of ASD.

Keywords: Atrial septal defect; Surgical ASD closure; Transcatheter ASD closure

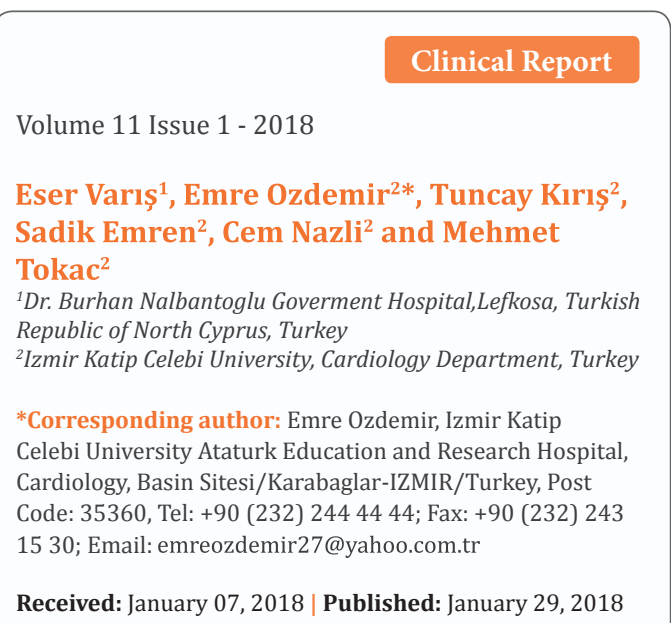

Received: January 07, 2018 | Published: January 29, 2018

\section{Introduction}

Atrial septal defect (ASD) is one of the most common congenital cardiac diseases [1]. ASD accounts for $7-10 \%$ of all congenital heart diseases in children and 30-33\% in adults. Although ASD usually asymptomatic, it can lead to exercise intolerance, atrial arrhythmia, right ventricular dysfunction, and pulmonary arterial hypertension. Guidelines recommend closure of ASD if right ventricular enlargement became regardless of symptoms in patients [2]. The main treatment option is percutaneous transcatheter closure and the other is surgical.

\section{Method}

We retrospectively evaluated the observational cohort who underwent transcatheter or surgical closure of ASD. Treatment options were determined according to the guidelines. We retrospectively collected patients' demographic characteristics, pre/post-procedure echocardiography outcomes, complication rates. 305 patients with ASDs who underwent closure were evaluated at the Cardiology Clinic of Katip Celebi University Ataturk Training and Research Hospital from 2006 until 2015. If necessary cardiac catheterization was performed, Qp/Qs calculation and ASD sizing was revealed. Heart Team consensus decided the selection of the most appropriate treatment (cardiologists, cardiac surgeons, anesthetists).

\section{Statistical Analysis}

Continuous variables were expressed as mean \pm standard deviation, and categorical variables were expressed as the number of patients together with the ratio of total count. Comparisons of parametric values between groups were made using Student's t-test or Mann-Whitney U-test depending on the situation. The Chi-square test was used to compare the categorical variables between the groups. Paired-samples T test was used to compare values before and after the procedure. A p-value $<0.05$ was considered statistically significant. All statistics were performed using SPSS version 17 (SPSS Inc., Chicago, IL, USA).

\section{Results}

Patients' baseline clinical and complaints was similar between group (Table 1). The $69.5 \%$ of the patients were female and $30.5 \%$ were male. The mean age of the patients was $35.6 \pm 14.6$. Dispne seen as the most common compliant of patients in $45 \%$ of the percutaneous treated group and $59 \%$ of the surgically treated group $(p=0.094)$ (Table 1$)$. Mitral regurgitation $(p=0.022)$, pulmonary stenosis ( $p<0.001)$, severe tricuspid regurgitation ( $p<0.001$ ) were more frequent in the surgical group. There was no difference between the groups in the concomitant cardiac anomalies (Table 1). Defect size was greater in surgical group $(24.8 \pm 9.2$ vs $18.9 \pm 6.4 p<0.001)$ (Table 1$)$. 
Table 1: Baseline clinical and echocardiographic feature of patients.

\begin{tabular}{|c|c|c|c|}
\hline Variable & $\begin{array}{l}\text { Transcatheter ASD Closure } \\
\text { (n:223) }\end{array}$ & $\begin{array}{l}\text { Surgical ASD Closure } \\
(\mathrm{n}: 82)\end{array}$ & p-Value \\
\hline Age (year) & $36.5 \pm 14.7$ & $33.2 \pm 13.8$ & 0.082 \\
\hline Sex (Male/Female) & $71 / 152$ & $22 / 60$ & 0.4 \\
\hline Hypertension, $\mathrm{n}(\%)$ & $28(13)$ & $6(7)$ & 0.197 \\
\hline Coronary Artery Disease, $\mathrm{n}(\%)$ & $9(4)$ & $2(3)$ & 0.146 \\
\hline Diabetes mellutis, n(\%) & $9(4)$ & $2(2)$ & 0.507 \\
\hline Cerebrovasculer Disease, $\mathrm{n}(\%)$ & $2(1)$ & $0(0)$ & 0.691 \\
\hline Cronic Renal Failure, n(\%) & $1(0.4)$ & $0(0)$ & 0.544 \\
\hline Complaint on application & & & 0.094 \\
\hline Dispne, $\mathrm{n}(\%)$ & $100(45)$ & $48(59)$ & \\
\hline Palpitation, $\mathrm{n}(\%)$ & $44(20)$ & $18(22)$ & \\
\hline Recurren Stroke, $\mathrm{n}(\%)$ & $2(1)$ & $0(0)$ & \\
\hline Chest Pain, $\mathrm{n}(\%)$ & $2(1)$ & $0(0)$ & \\
\hline Mitral regurgitation & & & 0.022 \\
\hline Mild, n (\%) & $94(42)$ & $38(46)$ & \\
\hline Moderate, $\mathrm{n}(\%)$ & $8(4)$ & $4(5)$ & \\
\hline Severe, $\mathrm{n}(\%)$ & $0(0)$ & $3(4)$ & \\
\hline Mitral stenosis & & & 0.213 \\
\hline Mild, n(\%) & $1(0.4)$ & $0(0)$ & \\
\hline Moderate, $\mathrm{n}(\%)$ & $0(0)$ & $1(1.2)$ & \\
\hline Severe, $\mathrm{n}(\%)$ & $0(0)$ & $0(0)$ & \\
\hline Aortic regurgitation & & & 0.49 \\
\hline Mild, n(\%) & $14(6)$ & $7(8)$ & \\
\hline Moderate, $\mathrm{n}(\%)$ & $0(0)$ & $0(0)$ & \\
\hline Severe, $\mathrm{n}(\%)$ & $0(0)$ & $0(0)$ & \\
\hline Aortic Stenosis & & & 0.544 \\
\hline Mild, n(\%) & $1(0.4)$ & $0(0)$ & \\
\hline Moderate, n (\%) & $0(0)$ & $0(0)$ & \\
\hline Severe, n (\%) & $0(0)$ & $0(0)$ & \\
\hline Tricuspid regurgitation & & & $<0.001$ \\
\hline Mild, n(\%) & $194(87)$ & $58(71)$ & \\
\hline Moderate, $\mathrm{n}(\%)$ & $23(10)$ & $8(10)$ & \\
\hline Severe, $\mathrm{n}(\%)$ & $2(1)$ & $4(15)$ & \\
\hline Tricuspid Stenosis & & & 0.544 \\
\hline Mild, n(\%) & $1(0.4)$ & $0(0)$ & \\
\hline Moderate, n(\%) & $0(0)$ & $0(0)$ & \\
\hline Severe, $\mathrm{n}(\%)$ & $0(0)$ & $0(0)$ & \\
\hline Pulmonary regurgitation & & & 0.525 \\
\hline
\end{tabular}




\begin{tabular}{|c|c|c|c|}
\hline Mild, $\mathrm{n}(\%)$ & $29(13)$ & $9(11)$ & \\
\hline Moderate, $\mathrm{n}(\%)$ & $2(4)$ & $2(2)$ & $<0.01$ \\
\hline Severe, $\mathrm{n}(\%)$ & $0(0)$ & $0(0)$ & \\
\hline Pulmonary stenosis & $9(4)$ & $4(5)$ & \\
\hline Mild, $\mathrm{n}(\%)$ & $0(0)$ & $1(1.2)$ & 0.661 \\
\hline Moderate, $\mathrm{n}(\%)$ & $0(0)$ & $7(9)$ & \\
\hline Severe, $\mathrm{n}(\%)$ & & & \\
\hline Concominant Cardiac Anomalies & $14(6)$ & $0(0)$ & \\
\hline PFO, $\mathrm{n}(\%)$ & $3(13)$ & $0(2)$ & $<0.001$ \\
\hline ISA, $\mathrm{n}(\%)$ & $7(13)$ & $24.8 \pm 9.2$ & \\
\hline EV, $\mathrm{n}(\%)$ & $1(0.4)$ & $18.9 \pm 6.4$ & \\
\hline PVRA, $\mathrm{n}(\%)$ & & & \\
\hline ASD Defect size (mm) & & & \\
\hline
\end{tabular}

PVRA: Pulmonary Venous Return Anomaly; PFO: Patent Foramen Ovale; ISA: Interatrial Septal Aneurysm; EV: Eustachian Valve; ASD: Atrial Septal Defect; n: Number

Mortality was higher in the surgical group $(\mathrm{p}=0.016)$. Minimal residual shunt, definated as shunt jet $<2 \mathrm{~mm}$ via color dopler echocardiography, was more occurred in percutaneous group ( $\mathrm{p}=0,016)$. Otherwise, major (need transfusion $>2$ units erythrocyte suspension) and minor bleeding $(\mathrm{p}<0.01)$, pericardial effusion $(p<0.01)$ and pneumothorax (p: 0.019) higher in the surgical group. Dehiscence was observed in 3 patients and device embolization was observed in 3 patients at percutaneous group, these ones underwent surgical operation. Permanent pacemaker was not required in both groups. In a patient with percutaneous closure, re-intervention was required. No statistical difference was observed between the groups in other complications (Table 2). Surgical procedure was performed with primary suture in $53 \%$ and graft in $48 \%$ of patients who underwent surgical closure. The $78 \%$ of transcatheter patients underwent balloon sizing.
$4 \%$ of transcatheter patients need to change the device during the procedure. Amplatzer device was used in 55\%, Cardi-O-Fix Occluders device in $42 \%$ and BioSTAR device in $2 \%$ of patients. The duration of hospital stay was higher in the surgical group ( $3 \pm 1.5$ days versus $12 \pm 4$ days, $p<0.001$ ). Treatment success rates were similar in both groups. (95\% versus $99 \%, p=0.139)$. Postoperative echocardiographic control were performed as 3 months after procedure on average (Table 3). In the light of these findings a significant reduction was observed in right atrium diameters after closure at transcatheter group $(\mathrm{p}<0.001)$, but not in the surgical group ( $\mathrm{p}=0.162$ ) (Table 3 ). Significant changes were observed in both the percutaneous closure and the surgical closure group before the procedure in left ventricle diastolic diameter, left ventricle systolic diameter, systolic pulmonary arterial pressure, right ventricular diastolic diameter (Table 3).

Table 2: Procedural complications.

\begin{tabular}{|c|c|c|c|}
\hline Variable & $\begin{array}{c}\text { Transcatheter ASD Closure } \\
(\mathbf{n : 2 2 3 )}\end{array}$ & $\begin{array}{c}\text { Surgical ASD } \\
\text { Closure (n:82) }\end{array}$ & p-Value \\
\hline Periprocedural shunt, $\mathrm{n}(\%)$ & $15(7)$ & $0(0)$ & 0.016 \\
\hline Major bleeding, $\mathrm{n}(\%)$ & $3(1)$ & $23(28)$ & $<0.01$ \\
\hline Minor bleeding, $\mathrm{n}(\%)$ & $1(0.4)$ & $27(33)$ & 0.065 \\
\hline Pleural effusion, $\mathrm{n}(\%)$ & $0(0)$ & $2(2.4)$ & $<0.01$ \\
\hline Pericardial effusion, $\mathrm{n}(\%)$ & $6(3)$ & $0(0)$ & 0.291 \\
\hline Occluder dehiscence, $\mathrm{n}(\%)$ & $3(1.3)$ & $0(0)$ & - \\
\hline Occluder thrombosis, $\mathrm{n}(\%)$ & $0(0)$ & $0(0)$ & 0.291 \\
\hline Cerebral infarction, $\mathrm{n}(\%)$ & $0(0)$ & $2(2.4)$ & 0.019 \\
\hline Device embolism, $\mathrm{n}(\%)$ & $3(1)$ & $0(0)$ & - \\
\hline Pneumothorax, $\mathrm{n}(\%)$ & $0(0)$ & $0(0)$ & 0.393 \\
\hline Permanent pacemaker implantation, $\mathrm{n}(\%)$ & $0(0)$ & $0(0)$ & 0.544 \\
\hline Arrhythmia, $\mathrm{n}(\%)$ & $5(2.4)$ & $0(0)$ & - \\
\hline Repeat operation, $\mathrm{n}(\%)$ & $1(0.4)$ & & \\
\hline Pulmonary edema, $\mathrm{n}(\%)$ & $0(0)$ & & \\
\hline
\end{tabular}

Citation: Varış E, Ozdemir E, Kırıș T, Emren S, Nazli C et al. (2018) An Experience of a Tertiary Center for 9 Years on Patients with Surgical and Percutaneous Closure of Atrial Septal Defects. J Cardiol Curr Res 11(1): 00369. DOI: 10.15406/jccr.2018.11.00369 
Table 3: Echocardiographic features of the patients before and after the procedure.

\begin{tabular}{|c|c|c|c|c|c|c|}
\hline & \multicolumn{3}{|c|}{ Transcatheter ASD Closure } & \multicolumn{3}{c|}{ Surgical ASD Closure } \\
\hline Variable & Pre-procedural & Post- precedural & p-value & Pre-procedural & Post- precedural & p-value \\
\hline RAD (mm) & $41.7 \pm 8.1$ & $34.3 \pm 6.6$ & $<0.001$ & $42.3 \pm 12$ & $35.2 \pm 7.9$ \\
\hline LVDD (mm) & $42.3 \pm 4.1$ & $44.8 \pm 4.0$ & $<0.001$ & $42.2 \pm 5.2$ & $45.8 \pm 4.7$ \\
\hline LVSD (mm) & $24.9 \pm 4.1$ & $26.2 \pm 4.1$ & $<0.001$ & $24.1 \pm 6.5$ & $28.6 \pm 4.4$ \\
\hline SPAP (mmH) & $41 \pm 11$ & $24.5 \pm 6$ & $<0.001$ & $37 \pm 18$ & $<0.001$ \\
\hline RVDD (mm) & $36.6 \pm 5.9$ & $29.9 \pm 4.2$ & $<0.001$ & $40.2 \pm 11.2$ & $<0.001$ \\
\hline
\end{tabular}

RAD: Right Atrium Diamater; LVDD: Left Ventricul Diastolic Diamater; LVSD: Left Ventricul Sistolic Diamater; SPAP: Sistolic Pulmoner Arterial Pressure; RVDD: Right Venricul Diastolic Diamater

\section{Discussion}

ASD is seen one in 1500 live births, more common in women. In accordance with this information in our study, the number of female patients was more than the number of male patients (Table 1). Percutaneous technique is increasingly evolving and this method becomes the dominant treatment option for ASD treatment as in our study (Table 1). In this study, deaths were observed in 2 patients who underwent surgery on long-term follow-up, with no relationship with ASD closure (Table 2). Surgical closure is a more invasive procedure so the perioperative mortality rate is partially affected by surgical intervention. Pericardial effusion, haemorrhage and arrhythmias are the most common complications observed in the literature on surgery group and late deaths did not related with the closure of ASD in both groups on studies [4]. Complications associated with transcatheter closure are pericardial effusion, femoral access point complications and device embolization [5]. Device embolization was observed at $1 \%$ in our study, dehiscence was observed at $1.3 \%$, one of this dehiscence needs percutaneous intervention and two others were followed without intervention (Table 2). In addition, pericardial effusion rate was $3 \%$ in percutaneous group and intervention was not needed. In our population, the most frequent complications were major-minor bleedings $(61 \%)$ and pericardial effusion $(24 \%)$ on the surgical group. On the other hand, arrhythmia was not observed in the surgical closure group (Table 2). In unclosed ASD, the risk of stroke and thromboembolism was reported to be $4 \%$ in patients with a mean age of 36.4 years [6]. Both methods have been shown to prevent these events in a similar rates [7]. In our study, cerebral infarction were not observed after closure in both groups as in the literature (Table 2). In some studies which acute heart failure develops due to a sudden increase in left ventricular preload after ASD closure [8], in our patient population, heart failure was not observed in patients in both groups(Table 2). Increased blood flow from ASD shunt results pulmonary hypertension (PH) with 6-27\% coincidence rate [9]. However, the shunt of ASD does not cause $\mathrm{PH}$ at all patients. This suggests that different mechanisms may play a role in the development of PH in some patients. Decrease in pulmonary artery pressures (PAP) is the first target of ASD closure [10]. In a study by De Lezo et al. [11], a 21-month followup showed an early and persistent PAP decrease that caused clinical improvement [11]. Veldtman et al. [12] that the expected systolic PAP values tend to normalize after ASD closure, in their study, systolic PAP decreased under $35 \mathrm{mmHg}$ in $29 \%$ of patients within one year [12]. In our study, the decrease in PAP after the procedure was significantly higher in the patients who underwent percutaneous closure (Table 3). ASD is the leading cause of chronic volume loading in the right atrium (RA) and right ventricle (RV) [13]. Progressive RA and RV dilation are associated with longterm arrhythmia and impairment of left ventricular function. RV remodelling begins within 24 hours after percutaneous closure and lasts for 6-8 weeks. Trees et al. [14] observed a decrease in the size of the right heart cavities after percutaneous closure [14]. In surgical studies, it has been found that the surgeon often fails to normalize the cardiac geometry [15]. In our study, both the surgical and percutaneous closure groups showed a significant decrease in the size of the RV. In our study, both the surgical and percutaneous closure groups showed a significant decrease in the size of the RV before the procedure (Table 3 ). Due to the stopped shunt from ASD, left ventricle (LV) diastolic diameters increases. Right ventricle dilatation before closure, directly septal slip from right to left and indirectly through the pericardium, restricts both LV size and filling. Thilen et al. [14] and Monfredi et al. [15] shown that post-procedural LV diastolic diameters and LV fractional shortening increase in both surgical and percutaneous closure patients $[14,15]$. Consistent with these study results above, we observed a significant increase in LV diameters after surgery in both our surgical and percutaneous closure groups (Table 3 ).

\section{Conclusion}

As a conclusion if the patients are evaluated and selected carefully, both surgical and percutaneous closure is convenient and successful in the treatment of ASD.

\section{References}

1. Geva T, Martins JD, Wald RM (2014) Atrial septal defects. Lancet 383(9932): 1921-1932.

2. Warnes CA, Williams RG, Bashore TM, Child JS, Connolly HM, et al (2008) ACC/AHA 2008 Guidelines for the Management of Adults with Congenital Heart Disease: A report of the American College of Cardiology/American Heart Association Task Force on Practice Guidelines (writing committee to develop guidelines on the management of adults with congenital heart disease). Circulation 52(23): e143-263. 
3. King TD, Mills NL (1974) Nonoperative closure of atrial septal defects. Surgery 75(3): 383-388.

4. Du ZD, Hijazi ZM, Kleinman CS, Silverman NH, Larntz K, et al. (2002) Comparison between transcatheter and surgical closure of secundum atrial septal defect in children and adults. JACC 39(11): 1836-1844.

5. Meier B, Lock JE (2003) Contemporary management of Patent Foramen Ovale. Circulation 107(1): 5-9.

6. Hoffmann A, Chockalingam P, Balint OH, Dadashev A, Dimopoulos $\mathrm{K}$, et al. (2010) Cerebrovascular accidents in adult patients with congenital heart disease. Heart 96(15): 1223-1226.

7. Kotowycz MA, Therrien J, Ionescu-Ittu R, Owens CG, Pilote L, et al (2013) Long-term outcomes after surgical versus transcatheter closure of atrial septal defects in adults. JACC Cardiovasc Interv 6(5): 497-503.

8. Schubert S, Peters B, Abdul-Khaliq H, Nagdyman N, Lange PE, et al. (2005) Left ventricular conditioning in the elderly patient to prevent congestive heart failure after transcatheter closure of atrial septal defect. Catheter Cardiovasc Interv 64(3): 333-337.

9. Sachweh JS, Daebritz SH, Hermanns B, Fausten B, Jockenhoevel S, et al. (2006) Hypertensive pulmonary vascular disease in adults with secundum or sinus venosus atrial septal defect. Ann Thorac Surg 81(1): 207-213
10. Humenberger M, Rosenhek R, Gabriel H, Rader F, Heger M, et al. (2011) Benefit of atrial septal defect closure in adults: impact of age. Eur Heart J 32(5): 553-560.

11. De Lezo J, Medina A, Romero M, Pan M, Segura J, et al. (2002) Effectiveness of percutaneous device occlusion for atrial septal defect in adult patients with pulmonary hypertension. AmHeart J 144(5): 877-880.

12. Veldtman GR, Razack V, Siu S, El-Hajj H, Walker F, et al. (2001) Right ventricular form and function after percutaneous atrial septal defect device closure. J Am Coll Cardiol 37(8): 2108-2113.

13. Campbell M (1970) Natural history of atrial septal defect. Br Heart ] 32(6): 820-826.

14. Monfredi O, Luckie M, Mirjafari H, Willard T, Buckley H, et al. (2013) Percutaneous device closure of atrial septal defect results in very early and sustained changes of right and left heart function. Int J Cardiol 167(4): 1578-1584.

15. Thilen U, Persson S (2006) Closure of atrial septal defect in the adult. Cardiac remodeling is an early event. Int J Cardiol 108(3): 370-375. 